\title{
DEVELOPMENT OF A TWO-STAGE AMT OPTION SELECTION MODEL TO USE IN TURKISH MANUFACTURING COMPANIES
}

\author{
Yusuf Tansel İç* \\ Department of Industrial Engineering, \\ Baskent University, Ankara, Turkey. \\ E-mail: ytansel@baskent.edu.tr \\ Mustafa Yurdakul \\ Department of Mechanical Engineering, \\ Gazi University, Ankara, Turkey. \\ E-mail: yurdakul@gazi.edu.tr
}

\begin{abstract}
Limited capital resources force manufacturing companies in Turkey to use systematic and thorough selection models in making their investment decisions in advanced manufacturing technologies (AMT). Various AMT selection models are available in the literature. However, the authors' literature survey and discussions with the potential buyers of AMTs showed that there is still a need for a selection model which should provide an optimal set of AMT options and consider strategic benefits along with financial and other constraints in a multi-level model. This study aims to develop such an AMT option selection model by obtaining the contributions of the AMT options into a manufacturing company's competitive strategy in its first level, and then incorporating them into a GP model along with financial and other constraints to select an AMT option set in its second level. A real-world case study is developed to illustrate the application of the proposed model.
\end{abstract}

Keywords: Strategic Evaluation, Advanced Manufacturing Technologies (AMT), AMT Selection Model, Analytic Hierarchy Process (AHP), Goal Programming

\section{Introduction}

Tight budgets force the manufacturing companies to make their selection decisions in advanced manufacturing technologies (AMT) correctly using systematic and thorough selection models. This paper aims to fill the need for a systematic and thorough model for Turkish manufacturing companies in their investments in available AMT options which are provided in Table 1.Various AMT selection procedures are available in the literature. Financial analysis is commonly performed to justify AMT investments by applying money-time relationships such as net present value method or internal rate of return method. However, since it is difficult to quantify the strategic benefits provided by AMTs in financial terms (Naik \& Chakravarty, 1992; Usher et al., 2001; Cardoso et al., 2012), several justification models are presented in the literature to evaluate strategic benefits provided by AMT (Kleindorfer \& Partovi, 1990; Kakati, 1997; Nagalingam \& Lin, 1997, 1998; Wabalickis, 1988; Ordoobadi \& Mulvaney, 2001; Aravindan \& Punniyamoorty, 2002; Kreng et al., 2011). There are also various efforts in the justification of AMT technologies that propose hybrid approaches to integrate economic and strategic considerations within the same model (Stam \& Kuula, 1991;Naik \& Chakravarty, 1992; Khouja, 1995; Shang \& Sueyoshi, 1995; Luong, 1998; Bokhorst et al., 2002; Yurdakul, 2004; Punniyamoorthy and Ragavan, 2003; Chan et al., 2006; Al-Ahmari,2008; Chuu, 2009; Wang and Chin, 2009).

\footnotetext{
Corresponding author
} 
Table 1. Advanced manufacturing technology options (Boyer \& McDermott, 1999, Yurdakul, 2004)

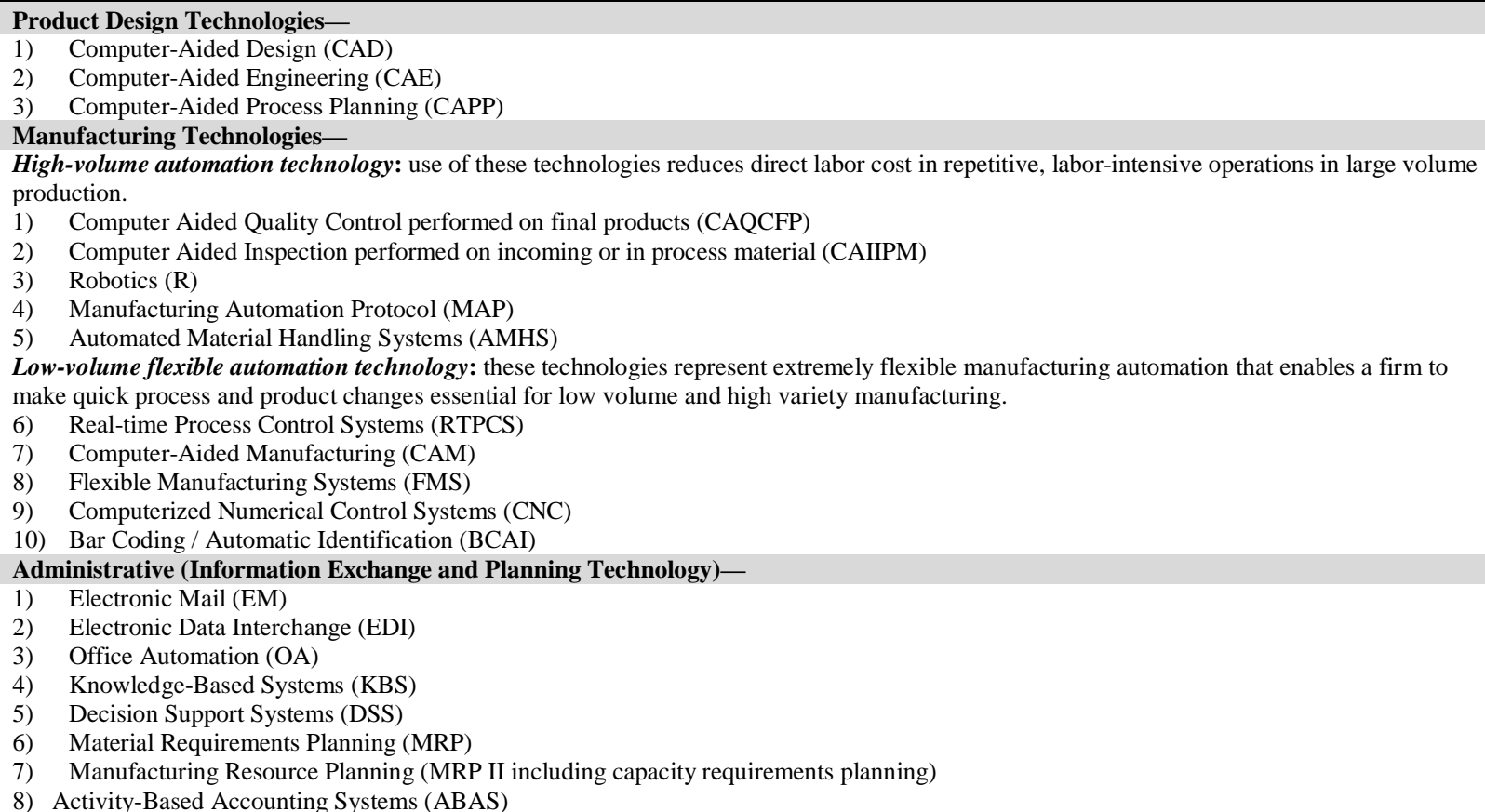

Based on the authors' AMT selection literature survey it can be stated that an AMT selection model should provide an optimal set of AMT options rather than just ranking them. It should also consider strategic benefits along with financial and other constraints in a multi-level model. In development of such selection models, goal programming (GP) is recommended in the literature (Lee and Kwak, 1999; Yurdakul, 2004). In this study, the contributions of the AMT options into a manufacturing company's competitive strategy are obtained first and then, they are incorporated into the GP model along with financial and other constraints to select an AMT option set as illustrated in Figure 1.

\section{The description the developed two-stage AMT selection model}

The manufacturing strategy criteria (cost, quality, flexibility, and delivery dependability) are placed in the first level of the developed AMT selection model (Figure 1). They are potential points of differentiation between a manufacturing company and its competitors (Kleindorfer and Partovi, 1990; Ghalayini et al., 1997; Kreng, 2011). AHP whose detailed explanation and characteristics can be found in Saaty (1988) and Yurdakul and Ic $(2004 ; 2005)$ is used to compute the relative importance (weights) of manufacturing strategy criteria for the competitive position of the company in its market with respect to its competitors. In Figure 1, below the manufacturing strategy criteria level, the twenty-one benefits, which are generated by the AMT options, are listed under 'BENEFITS' heading (Tompkins, 1989; Maleki, 1991; Luong 1998; Primrose, 1991). BENEFITS link the AMT options with the manufacturing strategy criteria in the model. The strategic evaluation approach developed in Naik\&Chakravarty (1992) is used to calculate the contributions of AMT options with respect to the manufacturing strategy criteria through the benefits by combining the contributions of AMT options to the benefits and the contributions of the benefits to the four criteria of the manufacturing strategy. 


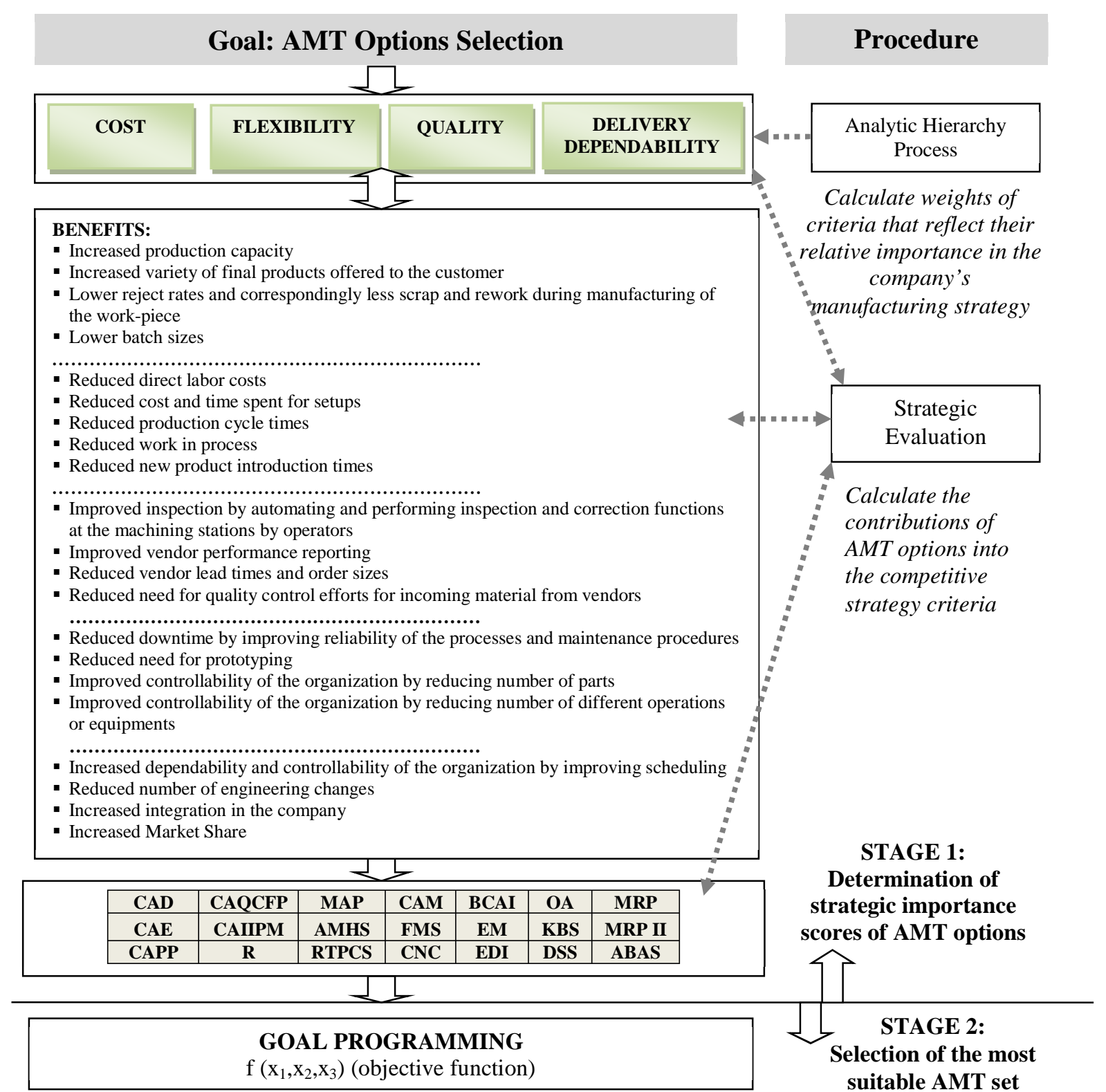

Figure 1. The developed two-stage AMT selection n

One of the five numbers [1 (N: Not Important), 2 (L: Low Importance), 3 (M: Medium Importance), 4 (H: High Importance) and 5 (V: Very Important)] is assigned for each contribution. The contributions of the AMT options to the four criteria of the manufacturing strategy $\left(c_{i j}\right)$ can be calculated with Eq. (1) using the contributions of AMT options to the twenty-one benefits $\left(a_{i k}\right)$ and the contributions of the benefits to the four manufacturing criteria $\left(b_{k j}\right)$.

$$
c_{i j}=\operatorname{Best}\left\{\operatorname{Worst}\left(a_{i k} ; b_{k j}\right) ; k=1, \ldots, 21\right\}
$$

Where,

$a_{i k} ; \mathrm{i}=1 \ldots$ number of AMT options; $\mathrm{k}=1 \ldots 21 \quad\left(a_{i k} ; \mathrm{N}, \mathrm{L}, \mathrm{M}, \mathrm{H}\right.$ or $\left.\mathrm{V}\right)$

$b_{k j} ; \mathrm{k}=1 \ldots 21$ BENEFITS; $\mathrm{j}=1 \ldots 4 \quad\left(b_{k j} ; \mathrm{N}, \mathrm{L}, \mathrm{M}, \mathrm{H}\right.$ or $\left.\mathrm{V}\right)$

$c_{i j} ; \mathrm{i}=1 \ldots$ number of AMT option alternatives; $\mathrm{j}=1 \ldots 9 \quad\left(c_{i j} ; \mathrm{N}, \mathrm{L}, \mathrm{M}, \mathrm{H}\right.$ or $\left.\mathrm{V}\right)$ 
Once the contributions of an AMT option to the four criteria $\left(c_{i j}\right)$ are calculated, they are multiplied with their respective criterion weight $\left(w_{j}\right)$ and summed to calculate strategic importance score of each AMT option $\left(I S_{i}\right)$ (Eq. (2)).

$$
I S_{i}=\sum_{J=1}^{4} c_{i j} \times w_{j}
$$

The outputs of the first stage (strategic importance scores of AMT options) are input to the second stage of the model along with other relevant budgetary or resource constraints to obtain the most suitable set of AMT options using GP model. The details of the GP model are provided in the following section.

\subsection{The description of the GP model used in the second stage of the model}

GP requires assignment of an integer-valued decision variable $X_{i}$ for each AMT option $i(i=1, \ldots, n$ (number of AMT options)). The decision variable $X_{i}$ takes 1 if AMT option $i$ is chosen in the optimal solution. Otherwise, $X_{i}$ takes the value of 0 . GP has the flexibility of allowing AMT options to be mutually exclusive, prerequisite or independent. Only mutually exclusive and prerequisite dependencies require constraints. Mutually exclusive options are defined as a set of AMT options wherein the acceptance of one option precludes the simultaneous acceptance of any other AMT option in the set (Yurdakul, 2004). Representation of mutually exclusive AMT options is as follows:

$$
\sum_{i \in M E S} X_{i} \leq 1
$$

Where, $M E S=$ set of mutually exclusive AMT options under consideration. On the other hand, prerequisite AMT options are two or more AMT options wherein the acceptance of one of them necessitates the prior acceptance of some other AMT option(s). For example, if AMT option $i$ can not be accepted unless AMT option $j$ is accepted, acceptance of AMT option $j$ is a prerequisite for acceptance of AMT option $i$. The representation of this contingency relationship is as follows:

$$
X_{i} \leq X_{j}
$$

The selection of the AMT options that would contribute the most to the manufacturing strategy is ensured with eq. (5). $G$ is added to the right hand side of Eq. (5) to provide an aspiration level whereas $I S_{i}$ represents the strategic importance score of AMT option $i$.

$$
\sum_{i=1}^{n} I S_{i} X_{i} \leq G
$$

Limitations on financial resources are considered in GP by donating the allocated amount of money for purchase of new AMT options as $C$ and initial cost of AMT option $i$ as $I C_{i}$ so that total initial cost constraint can be expressed as:

$$
\sum_{i=1}^{n} I C_{i} X_{i} \leq C
$$

A manufacturing company can also limit the spending for total annual operation and maintenance expense for its selected set of AMT options. If the maximum allowable annual amount of money for annual expenses is shown as $A E$ and annual maintenance and operation cost of AMT option $i$ as $m_{i}$, total annual cost constraint for the new AMT options can be formulated as:

$$
\sum_{i=1}^{n} m_{i} X_{i} \leq A E
$$

In the solution of GP model, the constraints that are considered as goal (soft) constraints are converted to goal constraints by changing the less than or equal signs to the equality signs by using the deviation variables (overachievement of a goal is represented by $d^{+}$and underachievement of a goal is shown as $d$ ) and incorporated into the GP objective function. The right-hand side of a goal constraint reflects the targeted level of the resource utilization. An illustrative GP formulation is presented in Eqs. (8-15). Resource limitations are considered more important than the judgmentally determined strategic 
importance scores of the AMT options. As such, they are placed at the higher priority than the AMT options' strategic importance scores in the GP objective function. The presented GP formulation can easily be rearranged or modified depending on the priorities of the decision makers and circumstances of the decision environment (Yurdakul, 2004).

$$
\begin{gathered}
\text { Min } \mathrm{Z}=\mathrm{P}_{\mathrm{IC}} \mathrm{d}_{\mathrm{IC}}{ }^{+}+\mathrm{P}_{\mathrm{IS}} \mathrm{d}_{\mathrm{IS}}{ }^{+}+\mathrm{P}_{\mathrm{AE}} \mathrm{d}_{\mathrm{AE}}{ }^{-} \\
\sum_{i=1}^{n} I C_{i} X_{i}+d_{I C}^{-}-d_{I C}^{+}=C \\
\sum_{i=1}^{n} m_{i} X_{i}+d_{A E}^{-}-d_{A E}^{+}=A E \\
\sum_{i=1}^{n} I S_{i} X_{i}+d_{I S}^{-}-d_{I S}^{+}=G
\end{gathered}
$$

Constraints:

Number of AMT options for the design department (DD);

$$
\sum_{i=1}^{k} X_{i} \leq a
$$

Number of AMT options for the manufacturing department (MD)

$\mathrm{p}>\mathrm{k}$ and $\mathrm{a}, \mathrm{b}$ integer value.

$$
\sum_{i=k+1}^{p} X_{i} \leq b
$$

$$
\begin{gathered}
\mathrm{X}_{\mathrm{i}}=0 \text { or } 1 \\
\mathrm{~d}_{\mathrm{IC}}{ }^{+}, \mathrm{d}_{\mathrm{IC}}{ }^{-}, \mathrm{d}_{\mathrm{AE}}{ }^{+}, \mathrm{d}_{\mathrm{AE}}{ }^{-}, \mathrm{d}_{\mathrm{IS}}{ }^{+}, \mathrm{d}_{\mathrm{IS}}{ }^{-} \geq 0
\end{gathered}
$$

Since it would be difficult and cumbersome for the users of the developed two-stage AMT selection model to make all required calculations by themselves, STAGE 1 and STAGE 2 of the two-stage model are programmed in MS EXCEL. The output of STAGE 1 is exported to Stage 2 and the SOLVER tool within MS EXCEL obtains the most suitable set of AMT options.

\section{An illustrative case study}

Application of the AMT selection model is illustrated with a manufacturing company which is located in Ankara, Turkey. The company considers flexibility as its most important manufacturing strategy criterion to meet varying customer's requirements and needs. Customers' order sizes change from a few to thousands. Although the company is heavily invested in machineries, it has a very active design and engineering department. The company aims to manufacture a wide range of products without sacrificing its performance in price, quality and delivery dependability criteria. In coming years, the company wants to improve its design, engineering and manufacturing capabilities and increase its internal integration and cooperation among its departments.

The company engineers in various departments prepared AMT options as shown in Figure 2. For the design and engineering department, the management prepared five mutually exclusive AMT options (Option 1-Option 5 in Figure 2) to improve its software and hardware systems. In all alternatives, engineers proposed to buy five personal computers (PC) with five CAD softwares. The proposed CAD software (CIROS ${ }^{\circledR}$ 3D simulation) is a primarily 3D solid modelling system, and its focus is primarily on the design and drafting areas of product development (Festo, 2010). In alternatives 2-5, five additional workstations (WS) and different software modules of CIROS are included. The proposed CAE module (FEM) in Option 2 adds the capability of building Finite Element (FE) models appropriate for the type of analysis required - stress, durability, dynamic response, optimization, thermal or motion over the CIROS $^{\circledR}$ 3D simulation. The computer-aided machining (CAM) module in CIROS $^{\circledR}$ Production in Option 3 brings additional capabilities such as NC tool path creation, machining simulation and NC path verification. CIROS $^{\circledast}$ Studio in Option 4 can simulate actual manufacturing of the part additionally (Festo, 2010). The fifth alternative (Option 5) links the CNC machines in the manufacturing plant with the design and engineering department by building a DNC system to manage NC codes by adding CIROS $^{\circledR}$ Automation Suite. In such a case, the NC codes can be downloaded to the CNC machines directly without human intervention (Festo, 2010). 
The company engineers first decided to purchase vertical machining centers to improve their manufacturing capabilities for the manufacturing department. The engineers proposed to buy at least one and at most two of the three different models of MAZAK machining centers, namely FH4000 (Horizontal- 3 Axis), PFH5800 (Horizontal- 3 Axis), and VARIAXIS 500 (Vertical- 5 Axis). Among the machining center alternatives, VARIAXIS 500 improves performance at production time and product quality. Its tilt and rotary table integrates and performs various operations on multiple faces of a part without changing the setup. Machining center alternatives are provided in Figure 2 as Option 6-Option 8. Another improvement area in the manufacturing department considered by company engineers is automated measurement of critical work-piece dimensions and reducing measurement times from hours to minutes. The engineers proposed FANAMATION COMERO 1004040 model (Option 9 in Figure 2) as CMMs. The expected measurement workload requires purchase of two CMMs.

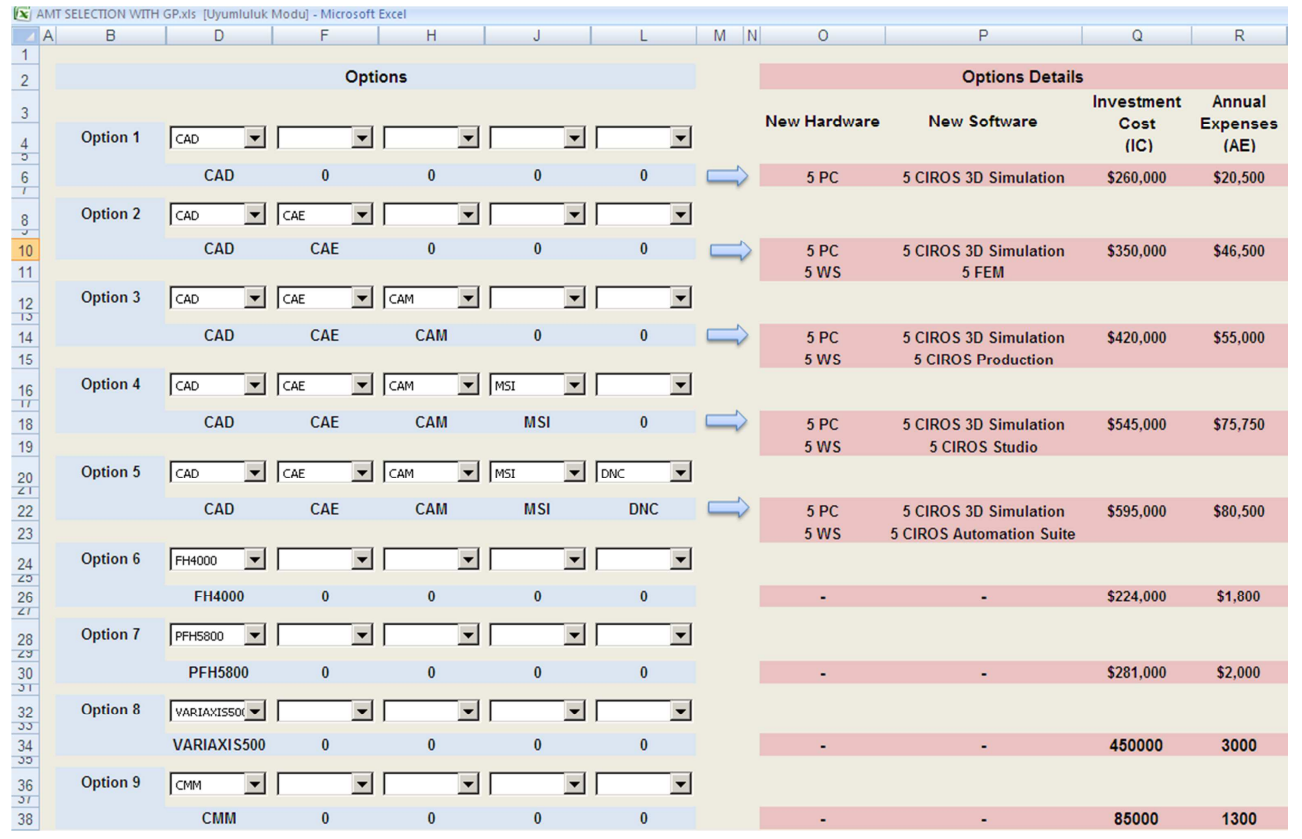

Figure 2. AMT Options

The company management put a limit of USD 2,000,000 and USD 750,000 for the total initial investment expense and total annual operating and maintenance expense respectively. In addition, the management put lower limits on the number of AMT options that can be selected to use in the design and manufacturing departments of the company. The calculation of strategic importance scores are performed in Figures 3-4, and the outputs of the first stage are presented in Figure 5. As an example, the strategic importance score of an AMT option 'Option-1' with respect to the manufacturing strategy criterion 'COST' is calculated as ' $\mathrm{M}$ ' in Eqs. (16-17) (see Figure 3):

$$
\begin{aligned}
& C_{1}=\operatorname{Best}\left\{\begin{array}{l}
\operatorname{Worst}(N ; N) ; \operatorname{Worst}(N ; L) ; \operatorname{Worst}(N ; M) ; \operatorname{Worst}(N ; H) ; \operatorname{Worst}(N ; L) ; \\
\operatorname{Worst}(N ; L) ; \operatorname{Worst}(N ; H) ; \operatorname{Worst}(N ; H) ; \operatorname{Worst}(N ; L) ; \operatorname{Wort}(N ; L) ; \\
\operatorname{Worst}(N ; M) ; \operatorname{Worst}(L ; N) ; \operatorname{Worst}(N ; V) ; \operatorname{Worst}(N ; N) ; \operatorname{Worst}(L ; N) ; \\
\operatorname{Worst}(N ; N) ; \operatorname{Worst}(M ; L) ; \operatorname{Worst}(L ; H) ; \operatorname{Worst}(M ; M) ; \operatorname{Worst}(L ; N) ; \\
\operatorname{Worst}(L ; N) ;
\end{array}\right\} \\
& C_{1}=\operatorname{Best}\{N, N, N, N, N, N, N, N, N, N, N, N, N, N, N, N, L, L, M, N, N\}=M
\end{aligned}
$$




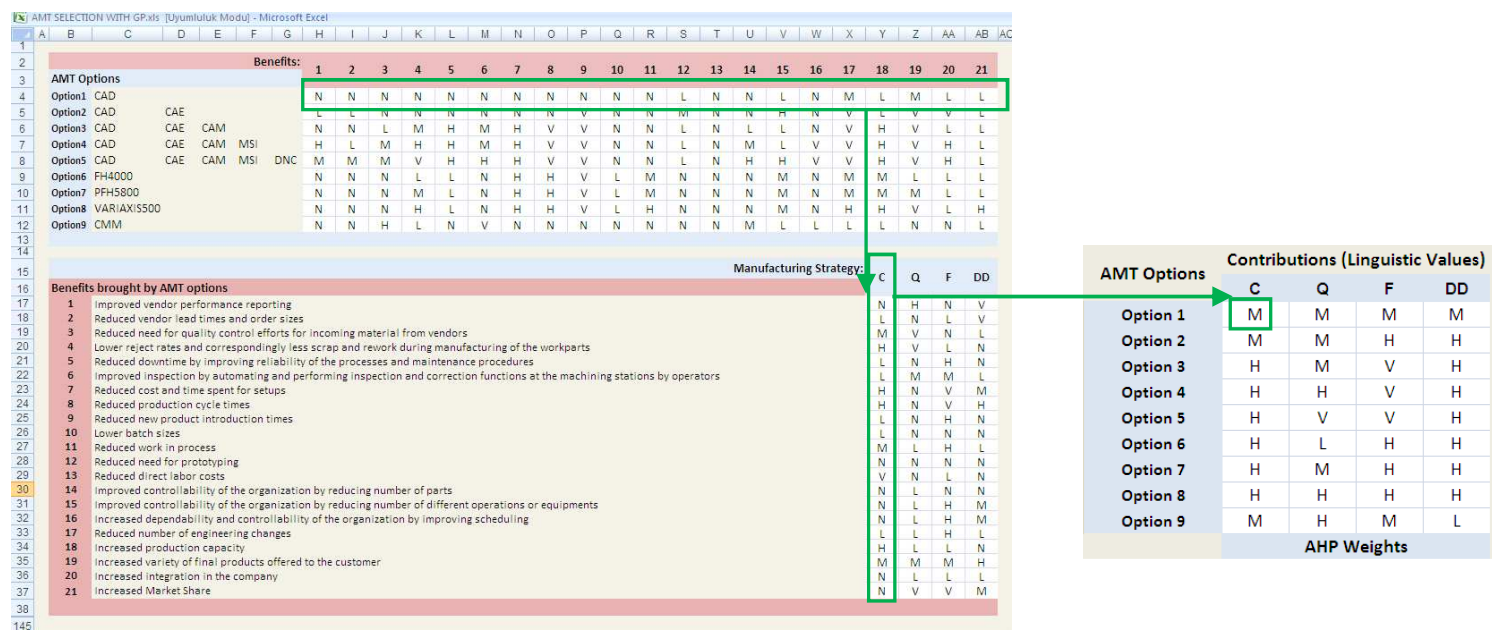

Figure 3. Calculation of contributions of AMT options to manufacturing strategy criteria

\begin{tabular}{|c|c|c|c|c|c|c|c|c|c|c|}
\hline \multicolumn{11}{|c|}{ 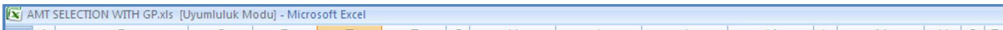 } \\
\hline 1 & B & c & D & E & $\mathrm{F}$ & $\mathrm{H}$ & 1 & J & & \begin{tabular}{l|llll}
$M$ & $N$ & $O$ & $P$ \\
\end{tabular} \\
\hline 2 & AHP & c & Q & $\mathrm{F}$ & DD & Norm & Pair- & Sompa & Matrix & Weights \\
\hline 3 & Cost & 1 & 0.16667 & 0.16667 & 1 & 0.07 & 0.07 & 0.07 & 0.09 & 0.08 \\
\hline 4 & Quality & 6 & 1 & 1 & 4 & 0.43 & 0.41 & 0.42 & 0.36 & 0.41 \\
\hline 5 & Flexibility & 6 & 1 & 1 & 5 & 0.43 & 0.41 & 0.42 & 0.45 & 0.43 \\
\hline 6 & Delivery Depen. & 1 & 0.25 & 0.2 & 1 & 0.07 & 0.10 & 0.08 & 0.09 & 0.09 \\
\hline 7 & Column Sum & 14.00 & 2.42 & 2.37 & 11.00 & 1.00 & 1.00 & 1.00 & 1.00 & 1.00 \\
\hline 8 & & & & $\begin{array}{l}4.0155 \\
0.0052\end{array}$ & & & & & & \\
\hline
\end{tabular}

Figure 4.The pairwise comparison matrice for calculation of manufacturing strategy criteria weights

\begin{tabular}{|c|c|c|c|c|c|c|c|c|c|c|c|}
\hline [x/A & $\begin{array}{c}\text { ELCTIONWTIH GP.X15 } \\
\text { B }\end{array}$ & 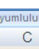 & $\frac{d u-M}{D}$ & $\begin{array}{c}\text { fitexce } \\
E\end{array}$ & & & & & & M & \\
\hline 16 & AMT Options & Contr & tions & guis & (alues) & & utions & nerical & & 18 & \\
\hline 17 & Alvi Uptions & c & Q & $\mathrm{F}$ & DD & c & Q & $\mathbf{F}$ & DD & 15 & RANK \\
\hline 18 & Option 1 & M & M & M & M & 0.5 & 0.5 & 0.5 & 0.5 & 0.500 & 9 \\
\hline 19 & Option 2 & M & M & H & H & 0.5 & 0.5 & 0.7 & 0.7 & 0.603 & 6 \\
\hline 20 & Option 3 & H & M & v & H & 0.7 & 0.5 & 0.9 & 0.7 & 0.705 & 3 \\
\hline 21 & Option 4 & H & H & $\mathrm{v}$ & H & 0.7 & 0.7 & 0.9 & 0.7 & 0.786 & 2 \\
\hline 22 & Option 5 & H & v & v & H & 0.7 & 0.9 & 0.9 & 0.7 & 0.867 & 1 \\
\hline 23 & Option 6 & H & L & H & H & 0.7 & 0.3 & 0.7 & 0.7 & 0.537 & 8 \\
\hline 24 & Option 7 & H & M & H & H & 0.7 & 0.5 & 0.7 & 0.7 & 0.619 & 5 \\
\hline 25 & Option 8 & H & H & H & H & 0.7 & 0.7 & 0.7 & 0.7 & 0.700 & 4 \\
\hline 26 & Option 9 & M & H & M & L & 0.5 & 0.7 & 0.5 & 0.3 & 0.564 & 7 \\
\hline 27 & & & & ights: & & 0.08 & 0.41 & 0.43 & 0.09 & & \\
\hline
\end{tabular}

Figure 5. Output screen of STAGE 1: Calculation of strategic importance scores and rankings of AMT options

Finally, the priority levels of the goals are determined and input in the GP Module screen along with other constraints and spending limits. The solution of the GP model will minimize the objective function (Eq. 18) and satisfy the goal constraints (Eqs. 19-21). The solution set should also satisfy the system constraints that are developed to formulate the dependencies among the AMT options (Eqs. 22-26) (Yurdakul, 2004).

$$
\text { Min } \mathrm{Z}=200,000 \times \mathrm{d}_{\mathrm{IC}}{ }^{+}+20,000 \times \mathrm{d}_{\mathrm{IS}}{ }^{-}+2,000 \times \mathrm{d}_{\mathrm{AE}}{ }^{+}
$$

Initial Cost Goal:

$$
\begin{gathered}
260,000 X_{1}+350,000 X_{2}+420,000 X_{3}+545,000 X_{4}+595,000 X_{5}+224,000 X_{6}+ \\
281,000 X_{7}+450,000 X_{8}+85,000 X_{9}+d_{I C}-d_{I C}{ }^{+}=2,000,000
\end{gathered}
$$

Total Annual Expenses Goal:

$$
\begin{gathered}
20,500 X_{1}+46,500 X_{2}+55,000 X_{3}+75,500 X_{4}+80,500 X_{5}+1,800 X_{6}+2,000 X_{7}+ \\
3,000 X_{8}+1,300 X_{9}+d_{A E}-d_{A E}{ }^{+}=750,000
\end{gathered}
$$


Manufacturing Strategy Goal:

$$
\begin{aligned}
& 0.500 \mathrm{X}_{1}+0.603 \mathrm{X}_{2}+0.705 \mathrm{X}_{3}+0.786 \mathrm{X}_{4}+0.867 \mathrm{X}_{5}+0.537 \mathrm{X}_{6}+0.619 \mathrm{X}_{7}+0.700 \mathrm{X}_{8}+ \\
& 0.564 \mathrm{X}_{9}+d_{I s}^{-}-d_{I S}^{+}=1.0
\end{aligned}
$$

Constraints:

$$
\begin{gathered}
\mathrm{X}_{1}+\mathrm{X}_{2}+\mathrm{X}_{3}+\mathrm{X}_{4}+\mathrm{X}_{5}<=1.0 \\
1.0<=\mathrm{X}_{6}+\mathrm{X}_{7}+\mathrm{X}_{8}<=2.0 \\
\mathrm{P}_{\mathrm{IC}}>\mathrm{P}_{\mathrm{IS}}>\mathrm{P}_{\mathrm{AE}} \\
\mathrm{X}_{\mathrm{i}}=0 \text { or } 1 \\
\mathrm{~d}_{\mathrm{IC}}{ }^{+}, \mathrm{d}_{\mathrm{IC}}{ }^{-}, \mathrm{d}_{\mathrm{AE}}{ }^{+}, \mathrm{d}_{\mathrm{AE}}^{-}, \mathrm{d}_{\mathrm{IS}}{ }^{+}, \mathrm{d}_{\mathrm{IS}}{ }^{-} \geq 0
\end{gathered}
$$

The obtained solution is presented in Figure 5. The two-stage AMT selection model recommended the purchase of the set of AMT options 'Option 5', 'Option 6', 'Option 8' and 'Option 9'. With the recommended selection the company will purchase five PCs loaded with CIROS ${ }^{\circledR}$ 3D simulation, five WSs loaded with CIROS ${ }^{\circledR}$ Automation Suite, Mazak FH4000, Mazak Variaxix-500 and two CMMs. The management found the results realistic and implementable.

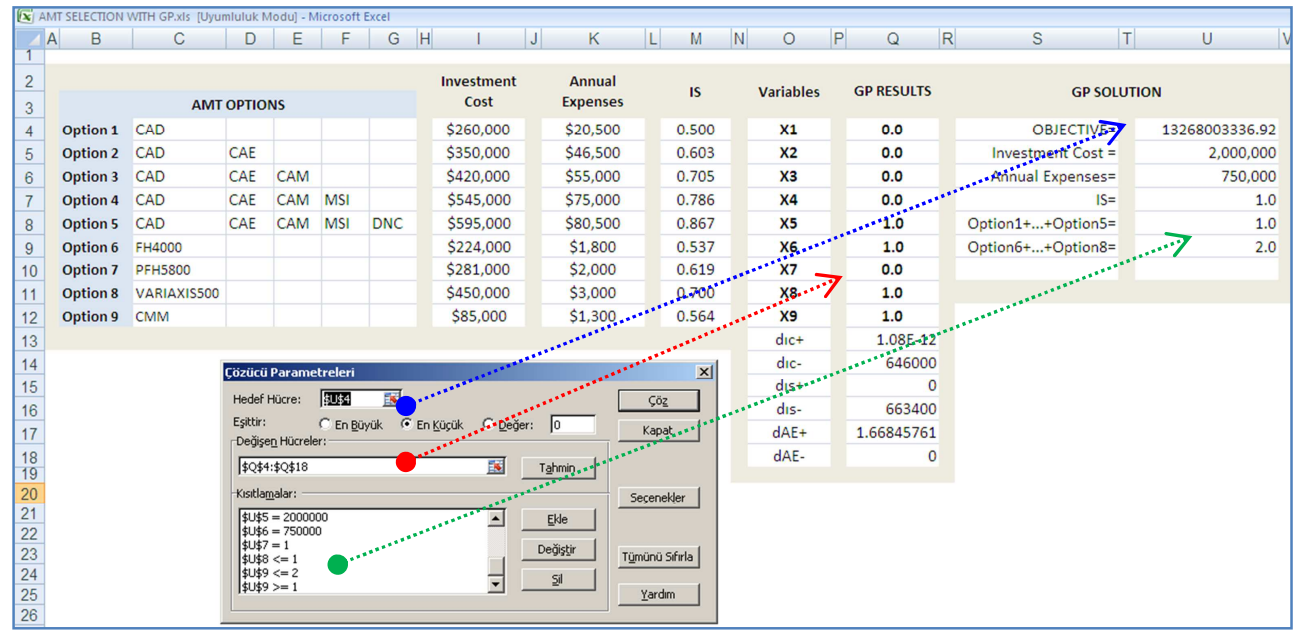

Figure 5. Output Screen of STAGE 2: The selected AMT set

\section{Conclusion}

The discussion with various manufacturing personnel involved in AMT selection decisions revealed that the developed model's ability to incorporate various different types of factors (strategic contributions, financial restrictions, dependencies, requirements, etc.) into the same model is seen as the most important aspect of the model. The two-stage selection model also helps the decision makers see different facets of the problem and keep track of their decisions in various stages on the recommended set of AMT options. Furthermore, it should be noted that the developed model possesses inherent flexibility to use in different production types such as mass, batch or job shop. One can also easily add new constraints, dependencies, benefits, manufacturing strategy criteria, AMT options or remove existing ones. However, difficulties and challenges exist, and they should be dealt with care. For example, obtaining the most suitable AMT options set is highly dependent on the proper selections of the benefits and assignment of correct weights in the first stage. Before making selections and assigning the numbers in the input screens of the first stage, an extensive and detailed discussion among the personnel from different departments of the manufacturing company is a necessity. It should not also be forgotten that the recommended set depends on the allocated budget for AMT purchase and proposed constraints. To conclude, once properly introduced and implemented in the AMT selection process, the two-stage model should improve the AMT selection process and consequently contribute to the profitability of Turkish manufacturing companies. 


\section{REFERENCES}

Al-Ahmari, A.M.A. (2008). A methodology for selection and evaluation of advanced manufacturing technologies. International Journal of Computer Integrated Manufacturing, 21(7), 778-789

Aravindan P, and Punniyamoorthy, M. (2002). Justification of advanced manufacturing technologies (AMT). International Journal of Advanced Manufacturing Technologies; 19, 151-156.

Bokhorst J.A.C., Slomp, J., and Suresh, N.C. (2002). An integrated model for part-operation allocation and investments in CNC technology. International Journal of Production Economic, 75, 267-285.

Boyer K.K. \& Mc Dermott C. (1999). Strategic consensus in operations strategy. Journal of Operations Management, 17, 289-305.

Cardoso, R.d R., Pinheiro de Lima, E., Gouvea da Costa, S.E.(2012). Identifying organizational requirements for the implementation of Advanced Manufacturing Technologies (AMT). Journal of Manufacturing Systems, 31, 367- 378.

Chan, F.T.S., Chan, H.K., Chan M.H., Humphreys, P.K. (2006). An integrated fuzzy approach for the selection of manufacturing technologies. Int J Adv Manuf Technol, 27, 747-758.

Chuu, S-J. (2009). Selecting the advanced manufacturing technology using fuzzy multiple attributes group decision making with multiple fuzzy information. Computers \& Industrial Engineering, 57, 10331042 .

Festo, (2010). The current range of producs from Festo Didactic, Learning Systems 2009/2010, Festo Didactic GmbH\&Co.KG.

Ghalayini, A. M., Noble, J. S., and Crowe, T. J. (1997). An integrated dynamic performance measurement system for improving manufacturing competitiveness. International Journal of Production Economics, 48, 207-225.

Kreng, V. B., Wu, C.Y., and Wang, I. C. (2011). Strategic justification of advanced manufacturing technology using an extended AHP model. Int J Adv Manuf Technol, 52,1103-1113.

Kakati M. (1997). Strategic evaluation of advanced manufacturing technology. International Journal of Production Economics, 53, 141-156.

Khouja, M. (1995). The use of data envelopment analysis for technology selection. Computers in Industrial Engineering, 28 (1), 123-132.

Kleindorfer, P.R., and Partovi, F.Y. (1990). Integrating manufacturing strategy and technology choice. European Journal of Operational Research, 47, 214-224.

Lee, C.W., and Kwak, N.K. (1999). Information resource planning for a health-care system using an AHP-based goal programming method. Journal of the Operational Research Society, 50, 1191-1198.

Luong LHS. (1998). A decision support system for the selection of computer-integrated manufacturing technologies. Robotics and Computer-Integrated Manufacturing, 14: 45-53. 
Maleki, R. A., (1991). Flexible Manufacturing Systems: The Technology and Management. Prentice Hall, Englewood Cliffs, N.J.

Nagalingam SV, and Lin GCI. (1997). A unified approach towards CIM justification. Computer Integrated Manufacturing Systems, 10(2), 133-145.

Naik, B., and Chakravarty, A.K. (1992). Strategic acquisition of new manufacturing technology: a review and research framework. International Journal of Production Research, 30(7), 1575-1601.

Ordoobadi, S.M., and Mulvaney, N.J. (2001). Development of a Justification Tool for advanced manufacturing technologies: system-wide benefits value analysis. Journal of Engineering and Technology Management, 18, 157-184.

Primrose PL. (1991). Investment in Manufacturing Technology. London, U.K: Chapman \& Hall.

Punniyamoorthy, M., Ragavan, P.V. (2003). A strategic Decision Model for The Justification of Technology Selection. International Journal of Advanced Manufacturing Technology, 21(1), 72-78.

Saaty, T.L. (1988). Multi-criteria Decision Making: The Analytic Hierarchy Process, McGraw-Hill, New York, 1980. Republished by University of Pittsburgh, Pittsburgh.

Shang J. and Sueyoshi T. (1995). A unified framework for the selection of a Flexible Manufacturing System. European Journal of Operational Research, 85, 297-315.

Stam A. and Kuula M. (1991). Selecting a flexible manufacturing system using multiple criteria analysis. International Journal of Production Research, 29(4), 803-820.

Tompkins, J.A. (1989). Winning Manufacturing: the how-to book of successful manufacturing. Norcross, GA: Industrial Engineering \& Management Press.

Usher, J.S, Kamal, A.H., and Kim, S.W. (2001). Decision support system for economic justification of material handling investments. Computers \& Industrial Engineering, 39 (1-2), 35-47.

Wabalickis, R.N. (1988). Justification of FMS with the analytic hierarchy process. Journal of Manufacturing Systems, 7(3), 175-182.

Wang, Y.M., and Chin, K.S. (2009). A new approach for the selection of advanced manufacturing technologies: DEA with double frontiers. International Journal of Production Research, 47(23), 66636679 .

Yurdakul, M. (2004). Selection of computer-integrated manufacturing technologies using a combined analytic hierarchy process and goal programming model. Robotics and Computer-Integrated Manufacturing, 20: 329-340.

Yurdakul, M., and İç, Y.T. (2004). AHP approach in the credit evaluation of the manufacturing firms in Turkey. International Journal of Production Economics, 88, 269-289.

Yurdakul, M., and İç, Y.T. (2005). Development of a performance measurement model for manufacturing companies using the AHP and TOPSIS approaches. International Journal of Production Research, 43, 4609-4641. 